\title{
Subcapsular Renal Hematoma
}

National Cancer Institute

\section{Source}

National Cancer Institute. Subcapsular Renal Hematoma. NCI Thesaurus. Code C115788.

A collection of blood between the renal capsule and the renal parenchyma. 